\title{
An Empirical Analysis of Employee Attitudes in Service Sector
}

\author{
Atul Gupta* \\ Sara Bennett \\ Meghan Moss \\ School of Business \& Economics, Lynchburg College, Lynchburg, VA 24501 \\ USA \\ E-mail: Gupta@Lynchburg.Edu
}

Angela Satya Gupta

School of Medicine, Virginia Commonwealth University, Richmond, Virginia

USA

Doi:10.5296/ijhrs.v3i4.4851

URL: http://dx.doi.org/10.5296/ijhrs.v3i4.4851

\begin{abstract}
The purpose of this paper is to empirically examine the relationship between sense of belonging and job satisfaction in hospital-based nurses. By discovering what contributes to job satisfaction, organizations will be able to better retain their nurses. This empirical paper used a non-experimental design to test a proposed model based on a review of relevant literature. Working nurses in a hospital setting completed surveys capturing the constructs researched. The findings of this research suggest that sense of belonging leads to positive outcomes and higher job satisfaction. Older employees tend to be less satisfied than their younger counterparts. While this study offers some insight into the factors affecting the job satisfaction of nurses, the sample was limited to respondents who were working at local hospitals in Southeastern United States. Thus these results may not represent the views of all nurses in the health care sector. To retain high-valued nurses it is important that an organization has a work environment that enhances their commitment to their occupation.
\end{abstract}

These research findings provide evidence that nurses who feel as though they are part of an organization will be more motivated to better their respective organizations. In turn, these profitable organizations invest back in the community they operate in, improving the overall socio-economic fabric of local economy. Although a considerable amount of research has been done evaluating the value of a sense of belonging, none of these studies link it to job satisfaction based on gender. This contribution is also of special importance amid the recent criticism of the healthcare costs by prominent management scholars.

Keywords - Sense of Belonging, Job Satisfaction, Healthcare, Age, Work Experience 
In recent years, American nursing staff has been at a shortage. Nurses have been working long hours and many nursing environments being are short-staffed. Though this has led to higher job security for employed nurses, many workers still choose to leave their current jobs due to dissatisfaction at the workplace.

High occupational turnover has become an issue for American hospitals and clinics. These organizations have been hard-pressed to retain current nursing staff as well as attract new nurses to their doors. Thus, nurse retention has become incredibly important to healthcare organizations as a whole. Employee sense of belonging has been shown to be integral to maintain both quality and quantity of nursing care, however previous studies on this subject have only applied this concept in educational settings. These studies have failed to explore the relationship between sense of belonging and job satisfaction for nurses beyond their student placement time (Winter-Collins \& McDaniel, 2000; Sedgwick and Yonge, 2008).

This study delves deeper into the relationship between sense of belonging and job satisfaction in hospital-based nurses. By determining what contributes to job satisfaction, organizations will be able to better retain their nurses and run their institutions more efficiently.

\section{Research Questions}

To address some of the knowledge deficits in the current literature, the following research questions were posed:

1. What demographic variables influence nurses' job satisfaction?

2. What is the impact of nurses' sense of belonging on his/her job satisfaction?

3. Do demographics have any influence on the relationship between sense of belonging and job satisfaction?

\section{Hypothesis}

We have hypothesized job satisfaction and sense of belonging have a positive relationship. Employees' satisfaction increases as they are surrounded my support. Because they look forward to coming to work, absentees and turnover rates decline. Many studies have looked further into the specific benefits of increased job satisfaction. These works, and other associated studies, are summarized here.

Sherman (2013) in his paper titled "Building a sense of community on nursing units" stated that since nurses invest a great amount of their time at work among people other than their families, a sense of belongingness is very crucial. There needs to be a strong bond among co-workers, so they can find support and strength during challenging and stressful times (professional or personal). Sherman hypothesized that a sense of belonging can be built by increasing interaction with others and participation in activities and events.

Nurses' sense of belonging can increase positive outcomes. When nurses feel that they are a part of a team they do all in their power ensure the team's success. They also may be more motivated to get more involved in the hospital's greater operations. Bellou (2006) stated that "the greater the extent to which employees feel they share the same experiences with "their" hospital, the more likely they will be to abide by its rules, embrace its policies and contribute as much as possible" (p. 30). Employees will be genuinely and actively concerned for the progress of the hospital because they are satisfied and proud. A sense of 
belonging brings about more open communications, confidence, respect, a sense of stability, and job retention.

Also when nurses are more satisfied with their jobs, patients are more satisfied with their care. A sense of belonging has not only proven to be a stepping stone towards workplace socialization, but learning as well. Employees become more comfortable with seeking advice to improve their performance as they become more confident and independent. Quality, respectable relationships with fellow unit workers make the daily operations and requests run more smoothly. Employees will not feel like they are have isolated experiences but rather will have the avenue to share similar experiences with each other and be a form of support and encouragement. This makes the challenges more bearable.

As research has shown, even before becoming working nurses, students need to feel that sense of belongingness during their training as well. Sedgwick and Yonge (2008) shared that the experience of the students at preceptorship can affect their future decisions. Students feel a sense of belongingness when they are welcomed and an effort is made by the experts they work with to know and include them in daily operations. Students who felt a sense of belonging reported that they felt safe, comfortable, and confident in their field. Their confidence grew through constant interaction with everyone they were in contact within the unit they were placed in. On the contrary, those who did not feel a sense of belonging felt angry, confused and other undesirable reactions. As a result, they were ostracized from the team. They were no longer confident in themselves, their performance, and about the nursing profession they had chosen to pursue. In addition, McDaniel and Winter-Collins (2000) stated that a supportive environment with strong interpersonal relationships can help students feel as though they are an integral part of the unit.

Hayhurst, et. al (2005) have done research on the relationship between nurse retention and the work environment. They described how job satisfaction is related to the experiences of the nurses on the job including the work environment, management style and support. The authors claimed that in order "to promote retention of nurses, healthcare organizations need to understand the factors that influence nurses' job satisfaction and feelings about their work setting." Thus, it is important to identify the variables and factors that influence job satisfaction. Hagerty (1990) introduced the concept of sense of belonging and its effects on job satisfaction of nurses. Based on Hagerty's work, sense of belonging is defined as "the experiences of personal involvement in a system or environment so that persons feel themselves to be an integral part of that system of environment." (p40). This is related to the idea of locus of control as well. The authors go on to discuss the impact that sense of belonging (or lack thereof) can have on individuals job satisfaction. (P38).

Winter-Collins \& McDaniel (2000) studied the relationship between sense of belonging and job satisfaction in a sample of novice nurses. They found a significant relationship between sense of belonging and job satisfaction. Nevertheless novice nurses may not have a good feel for the work environment, so these results of this study might be skewed. However there are several studies that suggest that that the quantity of time spent in a clinical placement is far less influential in nurses experience of belongingness than the quality of the support and guidance provided during that time (Battersby \& Hemmings, 1991; Oermann and Moffitt-Wolf, 1997). 
Garon \& Ringl (2004) described variables that influence job satisfaction of hospital-based registered nurses. These factors are : 1) working conditions including workload and staffing; 2) working environment; 3) salary \& benefits; 4) stress; 5) leadership issues; 6) role conflict and confusion; 7) professional recognition; 8) nurse - physician communication; 9) hours, shift and scheduling; and 10) sense of belonging.

Halfer and Graf (2006) described many factors that affect job satisfaction which fall under the umbrella of sense of belonging. These include effective working relationships, support from leaders, inclusion in the team, autonomy, and positive working relationships with physicians and surgeons.

Tillot et. al. (2013) agrees with other researchers that empowerment and interactions at work are positively correlated with job satisfaction. They stated that status (relative importance to others), certainty (ability to predict the future), autonomy, feelings of relatedness, and fair treatment can cause nurses to feel rewarded, which increases nurse engagement and improves the work environment. When nurses feel a sense of belonging and acceptance in the work place they feel more relaxed about their workload and thus are less likely to feel burnt-out and unsatisfied. Work becomes a more enjoyable experience.

\section{Method}

Nurses $(\mathrm{N}=1200)$ working in a major health care system in Virginia, USA were asked to fill in a questionnaire through e-mail. From those, 356 employees $(30 \%)$ participated in the survey. Only 354 questionnaires were usable for data analysis due to lack of information. $88 \%$ of the participants worked full-time (40 hours per week) and $12 \%$ worked part-time. In total, 304 female and 50 male employees participated in the study. 29\% were educated at community college and $71 \%$ at higher educational institutes and universities.

\section{Measures}

Sense of belonging was measured with the Sense of Belonging Instrument-Psychological (SOBI-P) (Hagerty \& Patusky, 1995). It is designed to measure a person's sense of being valued and fitting within an interpersonal relationship. The SOBI-P is 18 item instrument scored on a 4 point likert scale from strongly agree to strongly disagree. The items were summed up to create a sense of belonging score, with a high score indicating a higher sense of belonging. Cronbach's alpha coefficient for SOBI-P ranges from 0.91 to 0.93, demonstrating excellent reliability (Hagerty \& Patusky, 1995). Cronbach's alpha for the pilot study and current study were 0.88 and 0.90 respectively.

Job satisfaction was measured using McCloskey Mueller Satisfaction Scale (1990). This instrument is a multidimensional questionnaire designed for hospital staff nurses that measures satisfaction in 8 domains: satisfaction with extrinsic rewards, scheduling, family/work balance, co-workers, interaction, professional opportunities, praise/recognition, and control/responsibility. There are a total of 31 items on a five point likert scale from very dissatisfied (1) to very satisfied (5). The Cronbach's alpha coefficient for McCloskey Mueller Satisfaction questionnaire ranges from 0.89 to 0.90 demonstrating excellent reliability (Mueller \& McCloskey, 1990). The Cronbach's alpha for the pilot study and the current study were 0.81 and 0.82 respectively. 


\section{Research Model}

Figure 1: Research Model for Relationship between Sense of Belonging \& Job Satisfaction

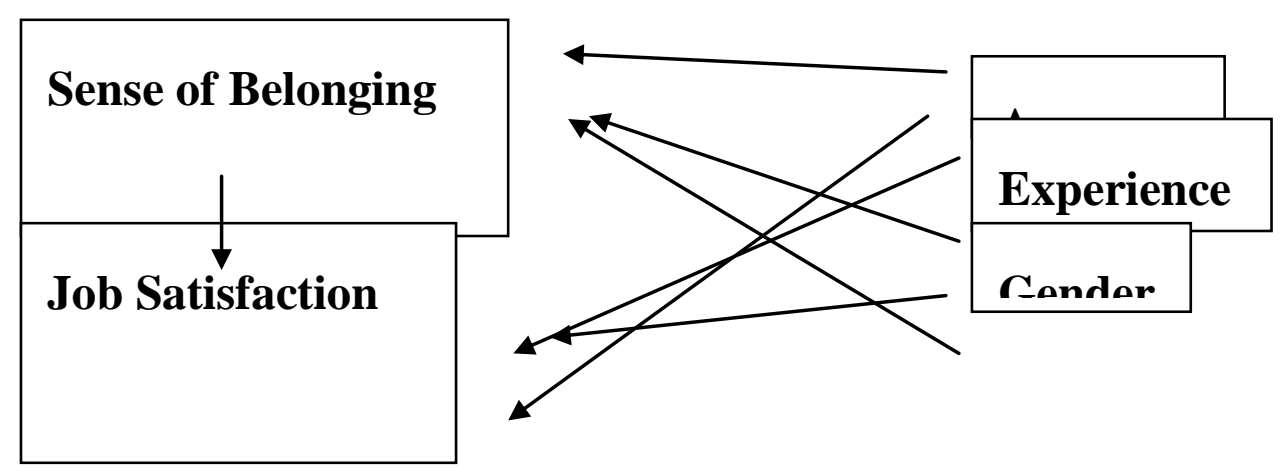

Table 1: Job Satisfaction and Sense of Belonging, Age, Employment, Experience, Gender

\begin{tabular}{|l|l|}
\hline & Job Satisfaction \\
\hline $\begin{array}{l}\text { Sense of } \\
\text { Belonging }\end{array}$ & $\mathbf{0 . 1 5}$ \\
\hline Age & $\mathbf{- 0 . 0 5 2} * *$ \\
\hline Employment & $\mathbf{0 . 0 0 0 2}$ \\
\hline Experience & $\mathbf{0 . 0 0 6}$ \\
\hline Gender & $\mathbf{0 . 0 2}$ \\
\hline R-squared & $\mathbf{0 . 1 5 5}$ \\
\hline$* \mathrm{p}<0.00 * \mathrm{p}<0.05$ \\
\hline
\end{tabular}

Table 2: Analysis Based on Gender

\begin{tabular}{|l|l|}
\hline Male & Job Satisfaction \\
\hline $\begin{array}{l}\text { Sense of } \\
\text { Belonging }\end{array}$ & $\mathbf{- 0 . 0 3}$ \\
\hline Age & $\mathbf{- 0 . 0 7 2 * *}$ \\
\hline Employment & $\mathbf{0 . 0 2}$ \\
\hline Experience & $\mathbf{- 0 . 0 3 1}$ \\
\hline R-squared & $\mathbf{0 . 0 7}$ \\
\hline$* p<0.00 \quad * * \mathrm{p}<0.05$ \\
\hline
\end{tabular}




\begin{tabular}{|l|l|}
\hline Female & Job Satisfaction \\
\hline $\begin{array}{l}\text { Sense of } \\
\text { Belonging }\end{array}$ & $\mathbf{0 . 1 7 5}$ \\
\hline Age & $\mathbf{- 0 . 0 5 * *}$ \\
\hline Employment & $\mathbf{0 . 0 0 2}$ \\
\hline Experience & $\mathbf{0 . 0 2}$ \\
\hline R-squared & $\mathbf{0 . 1 6}$ \\
\hline$* \mathrm{p}<0.00 \quad * * \mathrm{p}<0.05$ \\
\hline
\end{tabular}

\section{Discussion of Results}

A regression analysis was completed to calculate the relationships between job satisfaction and various variables (Table 1). We found that the job satisfaction-sense of belonging association had a positive relationship. Additionally, older employees tend to be less satisfied than their younger counterparts.

Contrary to our expectations, gender turned out not to be statistically significant variable. Given that women dominate the nursing profession, we found the absence of a gender effect surprising and decided to probe further. Sub-group analysis was conducted with men-only and women-only sub-groups (Table 2). As before, we found that job satisfaction varies inversely with age for both men and women. However, the decline in satisfaction appears to occur more rapidly in men than in women. Additionally, sense of belonging now appears to be a statistically significant contributor to job satisfaction for women only, a distinction that was lost to us in the overall model because of the way gender entered into our original specification.

\section{Conclusion}

Sense of belonging is a basic human need. Humans relish a sense of community, acceptance, connectivity, and trust. This need is applicable to not only social interactions, but also work relationships. When employees feel valued by their company and co-workers, this translates to better performance in the workplace. The results of this study show that nurses are no exception; a feeling of belongingness can result in positive outcomes such as higher job satisfaction.

Our conclusions are supported by many previous studies done on this subject. As detailed previously, Sherman (2013) stated a sense of belongingness is vital so nurses may have a support system. The results of this study support their finding as well the findings of McDaniel and Winter-Collins (2000) which argue that there is a significant relationship between sense of belonging and job satisfaction. Stechmiller and Yarandi (1992) also found that sense of belonging with valued and meaningful involvement would lead to higher job satisfaction.

The results of this study are not in line with the conclusion of Rhodes (1983) as well as Kacmar and Ferris (1989) that state that age and job satisfaction are positively associated. As nurses move further in their career, one would assume that they would have higher job satisfaction because they have moved up the career ladder into better positions. Also, at this point they would have already sorted through alternative careers and chosen a path that best 
suits their strengths and interests. However, since nursing is a physically demanding profession it could lead to dissatisfaction as employees age.

\section{Limitations}

Our study has limitations that need to be noted and addressed. First, this study was only conducted with nurses. It is possible that these results would not extend to other healthcare professionals such as physicians, pharmacists, etc. Additionally, our sample had a disproportionately large amount of females since nursing is a female dominated profession. It could be possible that the conclusions are sex-specific. Additional research with a larger and broader sample would give us further insight into this issue. When interpreting these data the small sample size must also be kept in mind. In addition, this study was cross-sectional in nature. In the future to adequately test the conceptual notions presented in terms of career stages, longitudinal studies should be conducted.

Most of the previous studies in this area have been conducted in educational settings. It may be difficult to generalize results based on the few studies conducted in the heath care setting. It may be worthwhile to conduct a meta-analysis synthesize our results with previous studies.

We also experienced small survey response rates that could have introduced a type II error in this study (Groves, Ciadini \& Couper, 1992). The nurses may have hesitated in sharing their opinion out of fear of their responses being shared with their employer. This study could be replicated with a larger sample size in order to determine the real strength of this linear relationship.

The R-squared value of 0.15 indicates that the explanatory power of our model is quite weak and suggests that the current specification may be lacking one of more important independent variables. An examination of the $\mathrm{R}^{2}$ and adjusted- $\mathrm{R}^{2}$ indicates that the goodness-of-fit of the women-only regression exceeds that of the men-only regression, which again suggests that important explanatory variables are missing from the analysis. A comparison of subgroup analysis, however, hints at the possibility that the missing variables might be gender-specific (i.e., the variable(s) missing from male only model might not be the same variable(s) missing from female only model).

\section{References}

Battersby, D. and Hemmings L. (1991). Clinical performance of university nursing graduates. Australian Journal of Advance Nursing.; Vol. 9, pp. 30-34.

Bellou, V., \& Thanopoulos, J. (2006). Enhancing Service Quality in a Hospital Setting. Review Of Business, 27(1), 26-32.

Garon, M., \& Ringl, K. K. (2004). Job satisfaction-based registered nurses. Journal of Clinical Innovations, 7(2), 1-48.

Groves R. M., Cialdini R. and Cooper M., P. (1992). Understanding the decision to participate in a survey. Public Opinion Quartely, Vol. 56, pp. 475-495. 
Hagerty, B. M., \& Patusky, K. (1995). Developing a measure of sense of belonging. Nursing Research, Vol. 44, pp. 9- 13.

Halfer, D. and Graf, E. (2006). "Graduate Nurse Perceptions Of The Work Experience." Nursing Economic, Vol. 24 No. 3, 150-155.

Hayhurst, A., Saylor, C. and Stuenkel, D. (2005). "Work Environmental Factors And Retention Of Nurses." Journal Of Nursing Care Quality, Vol. 20 No. 3, 283-288.

Kacmar, K. M., \& Ferris, G. R. (1989). Theoretical and methodological considerations in the age-job satisfaction relationship. Journal of Applied Psychology, 74(2), 201-207.

Mueller, C.W. and McCloskey, J.C. (1990).Nurses' job satisfaction: a proposed measure. Nursing Research, Vol. 39, pp. 113-117.

Oermann, M. and Moffitt-Wolf. A. 1997. New graduates perceptions of clinical practice. The Journal of Continuing Education in Nursing. 28(1):20-25.

Rhodes, S. R. (1983). Age-related differences in work attitudes and behavior: A review and conceptual analysis. Psychological Bulletin, 93, 328-367.

Sedgwick, M.G. and Yonge, O. (2008). 'We're it', 'We're a team', 'We're family' means a sense of belonging. Rural and Remote Health, Vol. 8, pp. 1021 Available: http://www.rrh.org.au

Sherman, R. (2013). Building a sense of community on nursing units. American nurse today, Vol. 8 No. 3, pp. 32-34

Stechmiller, J.K. and Yarandi, H.N. (1992). Job satisfaction among critical care nurses, American Journal of Critical Care, Vol. 1, pp. 37-44

Tillott, S., Walsh, K., \& Moxham, L. (2013). Encouraging engagement at work to improve retention. Nursing Management, 19(10), 27-31.

Winter-Collins, A., \& McDaniel, A. (2000). Sense of belonging and new graduate job satisfaction. Journal For Nurses In Staff Development: JNSD: Official Journal Of The National Nursing Staff Development Organization, 16(3), 103-111. 